\title{
Impaired endothelial function in siblings of patients with diabetic mellitus type 2
}

\author{
Yousef Rasmi ${ }^{1,2^{*}}$, Kani Emamy-Nagadeh ${ }^{3}$, Neda Valizadeh ${ }^{4}$, Masoud Saleh-Mogadam ${ }^{3}$, Alireza Shirpoor ${ }^{5}$ \\ and Ehsan Saboory ${ }^{6}$
}

\begin{abstract}
Background: Endothelial dysfunction is considered as a risk factor for cardiovascular disease, which is a consistent finding in diabetic mellitus type 2 (DMT2). First-degree relatives of DMT2 patients have a higher risk of developing DMT2 later on the life. We aimed to investigate whether impaired endothelial function exists in siblings of DMT2 patients.

Methods: As endothelial function markers, plasma E-selectin, soluble inter-cellular adhesion molecule-1 (sICAM-1), and endothelin-1 (ET-1) were measured on 27 DMT2 patients ( 9 m/18f; mean age: $48.48 \pm 6.75$ years), 28 siblings of DMT2 patients ( $14 \mathrm{~m} / 14 \mathrm{f}$; mean age: $44.54 \pm 7.10$ years), and 30 control subjects ( $18 \mathrm{~m} / 12 \mathrm{f}$; mean age: $44.72 \pm 7.56$ years) without any family history of diabetes. All the groups were matched by gender, age, and body mass index (BMI).

Results: Plasma levels of ET-1, sICAM-1, and E-selectin were significantly higher in the DMT2 group compared to the control group (ET-1:0.79 $\pm 1.63 \mathrm{pg} / \mathrm{ml}$ vs. $0.33 \pm 0.08 \mathrm{pg} / \mathrm{ml} ; \mathrm{P}_{\mathrm{CD}}=0.049$, slCAM-1: $71.15 \pm 27.20 \mathrm{ng} / \mathrm{ml}$ vs. $34.57 \pm 22$. $56 \mathrm{ng} / \mathrm{ml} ; P_{C D}=0.001$, E-selectin: $22.45 \pm 11.57 \mathrm{ng} / \mathrm{ml}$ vs. $\left.16.28 \pm 7.50 \mathrm{ng} / \mathrm{ml} ; P_{C D}=0.026\right)$. There was a significant difference in sICAM-1 levels between siblings $(62.08 \pm 26.37 \mathrm{ng} / \mathrm{ml})$ and controls $\left(P_{C S}=0.002\right)$, but not between siblings and DMT2 patients $\left(P_{S D}=0.411\right)$. Moreover, a significant difference was observed in ET-1 levels between siblings $(0.75$ $\pm 1.26 \mathrm{pg} / \mathrm{ml}$ ) and controls $\left(P_{C S}=0.031\right)$, but not between siblings and DMT2 patients $\left(P_{S D}=0.751\right)$. There was also a significant difference in E-selectin levels between DMT2 patients and siblings $\left(16.56 \pm 8.71 \mathrm{ng} / \mathrm{ml}\right.$; $\left.P_{S D}=0.028\right)$; however, the difference in E-selectin levels was not statistically significant between siblings and controls $\left(P_{C S}=0.919\right)$.

Conclusion: Endothelial function markers in the siblings of DMT2 patients are increased in comparision to the control group Therefore; family history in the DMT2 patients seems to be a risk factor for endothelial function. Furthermore, endothelial dysfunction is available very early in the DMT2 patients, even before overt hyperglycemia ensues (in siblings), and may play a key role in the etiopathology of the vasculopathy associated with DMT2.
\end{abstract}

Keywords: Siblings, Endothelial dysfunction, Diabetes mellitus, First-degree relatives

\section{Background}

The endothelial cell lines the internal lumen of all the vasculatures and serves as an interface between circulating blood and vascular smooth muscle cells [1]. Endothelium serves as a physical barrier between the blood and tissues. Morover, it is able to respond to chemical and physical signals by production of a wide range of factors that

\footnotetext{
*Correspondence: rasmiy@umsu.ac.ir

${ }^{1}$ Cellular and Molecular Research Center, Urmia University of Medical Sciences, Urmia, Iran

${ }^{2}$ Department of Biochemistry, Faculty of Medicine, Urmia University of Medical Sciences, Urmia, Iran

Full list of author information is available at the end of the article
}

regulate vascular tone, cellular adhesion, smooth muscle cell proliferation, and vessel wall inflammation [2].

Endothelial dysfunction has been reported in cardiovascular and metabolic disorders such as coronary heart disease [3], diabetic mellitus type I (DMT1), and diabetic mellitus type II (DMT2) [4]. The role of endothelial dysfunction is proved to be more complicated in DMT2 than in DMT1. Moreover, the effects of hyperlipidemia, aging, hypertension, and other factors add to the problem complexity [5-7]. Endothelial dysfunction and inflammation, as indicated by abnormal flow-dependent vasodilatation, increase circulating levels of adhesion molecules, soluble intercellular adhesion molecule-1 
(sICAM-1), and E-selectin [8] known to occur in patients with DMT2 $[9,10]$.

E-selectin is a cell adhesion molecule expressed only on endothelial cells activated by cytokines. Like other selectins, it plays an important part in inflammation [11]. During inflammation, E-selectin plays an important role in recruiting leukocytes to the site of injury. The local release of cytokines IL- 1 and TNF- $\alpha$ by damaged cells induces the over-expression of E-selectin on endothelial cells of nearby blood vessels [12].

ICAM-1 is a member of the immunoglobulin superfamily. Moreover, ICAM-1 is regarded as a transmembrane protein possessing an amino-terminus extracellular domain, a single transmembrane domain, and a carboxyterminus cytoplasmic domain [13].

On the other hand, endothelin-1 (ET-1), a potent vasoconstrictor peptide, is potentially involved in the vasomotor dysregulation of patients with diabetes as well as in the development of their vascular complications $[14,15]$. Further, both hyperglycaemia and insulin administration elevate circulating levels of ET-1 $[9,10]$. As ET-1 plays a pathophysiologic role in various forms of cardiovascular disease, it has been suggested to be a potential factor in endothelial dysfunction [16].

In fact, markers of endothelial function are often elevated years before any sign of microangiopathy becomes evident [5-7]. First-degree relatives (FDR) of DMT2 patients are at increased risk of coronary artery disease and also have a lifetime risk of developing DMT2 of up to $40 \%$ [17]. Development of these dysfunctions appears to be predicted by the presence of features of insulin resistance and associated clustering of atherosclerotic risk in these subjects [18]. In addition to the insulin resistance found in young FDRs [19, 20], family studies have revealed that FDRs of individuals with DMT2 are about 3 times more likely to develop DMT2 than individuals without a positive family history of the disease [21, 22].

This research aimed to assess endothelial function in FDRs and compare it with that in DMT2 and normal subjects. Moreover, considering that diabetic patients display altered endothelial function, we designed the present study so that circulating levels of endothelial function markers could be assessed in patients with DMT2 and their siblings.

\section{Methods}

\section{Subjects}

The participants in this study included 27 patients with DMT2, 28 siblings of DMT2 patients, and 30 control subjects with an age range from 30-60 years. Nonsmoker patients who had DMT2 after the age of 30 were only classified as having DMT2 and therefore, included in the study. Patients were then asked to encourage their siblings to participate in the study and the significance of the study was clarified to those willing to participate. Further, siblings of type 2 diabetic patients, matched for age, gender and body mass index (BMI) were studied.

Control subjects without personal or close family history of DMT2 were then selected to be matched with the DMT2 patients and their siblings in terms of age, gender and BMI. This study was conducted in accordance with the Declaration of Helsinki [23], and its revised version was ultimately accepted by the Ethics Committee of UMSU, Urmia, Iran. All the patients were required to give written informed consent prior to participating in the study.

\section{Blood specimens}

Peripheral heparinized blood samples $(5 \mathrm{ml})$ were collected from the subjects in the morning after an overnight fasting in clean glass tubes and then centrifuged at $3000 \mathrm{rpm}$ for $6 \mathrm{~min}$. The plasma was then separated and stored at $-80{ }^{\circ} \mathrm{C}$ until analysis.

\section{Assessment of endothelial function markers and fasting blood sugar (FBS)}

All the obtained samples were subjected to the following investigations: 1) Determining plasma concentrations in sICAM-1, ET-1, and sE-selectin using enzyme-linked immunosorbent assay kits (IBL; North America), 2) Determining plasma fasting blood sugar according to the glucose oxidase method (ZistChemi Diagnostics; Iran) using an autoanalyzer.

\section{Exclusion criteria}

Subjects were carefully selected to exclude conditions that could interfere with endothelial dysfunction markers, including coronary heart disease, smoking, hypertension, bronchial asthma, acute or chronic inflammatory diseases, autoimmune diseases, and medications like steroids and antipsychotic drugs.

\section{Statistical analysis}

Mean and $P$ values were estimated using SPSS (version 18 ). Results are expressed as mean \pm SD. Moreover, multiple comparison tests were performed using ANOVA, followed by LSD and post-hoc analysis to locate any differences. A $P$-value less than 0.05 indicated statistical significance.

\section{Results}

The demographic and clinical characteristics of the experimental population are listed in Table 1. Twentyseven patients with DMT2 (33.3\% male), 28 siblings of DMT2 patients (50\% male), and 30 control individuals (60\% male) were studied. Duration of disease in the DMT2 patients was $92.89 \pm 67.97$ month. The results showed significant differences in fasting blood sugar 
Table 1 Clinical and laboratory characteristics of study participants

\begin{tabular}{|c|c|c|c|c|c|c|}
\hline Variable & Control & Siblings & DMT2 & $P_{C S}$ & $P_{C D}$ & $P_{S D}$ \\
\hline Age (year) & $44.72 \pm 7.56$ & $44.54 \pm 7.10$ & $48.48 \pm 6.75$ & 0.99 & 0.17 & 0.11 \\
\hline $\operatorname{Sex}(M / F)$ & $18 / 12$ & $14 / 14$ & $9 / 18$ & 0.44 & 0.10 & 0.21 \\
\hline BMI $\left(\mathrm{kg} / \mathrm{m}^{2}\right)$ & $28.81 \pm 4.51$ & $30.64 \pm 5.87$ & $28.65 \pm 3.84$ & 0.17 & 0.96 & 0.13 \\
\hline Systolic blood pressure (mm Hg) & $131.4 \pm 07.6$ & $140.8 \pm 15.1$ & $145.1 \pm 11.7$ & 0.006 & $<0.001$ & 0.19 \\
\hline Diastolic blood pressure (mm Hg) & $88.1 \pm 09.9$ & $117.6 \pm 147.7$ & $93.7 \pm 11.9$ & 0.22 & 0.81 & 0.31 \\
\hline Disease period (month) & 0 & 0 & $92.89 \pm 67.97$ & - & - & - \\
\hline Fasting blood sugar (mg/dl) & $82.99 \pm 6.46$ & $89.25 \pm 7.69$ & $187.08 \pm 50.79$ & 0.452 & $<0.001$ & $<0.001$ \\
\hline
\end{tabular}

DMT2 diabetes mellitus type $2, P_{C S} P$ value between controls and sibling, $P_{C D} P$ value between controls and DMT2, $P_{S D} P$ value between DMT2 and sibling

levels in the DMT2 patients $(187.08 \pm 50.79 \mathrm{mg} / \mathrm{dl})$ compared to those in the siblings $(89.25 \pm 7.69 \mathrm{mg} / \mathrm{dl})$ and the controls $(82.99 \pm 6.46 \mathrm{mg} / \mathrm{dl})(p<0.0001$, for both $)$. However, the difference in plasma glucose levels between the siblings and the control individuals was not statistically significant ( $p=0.452)$, as shown in Table 1 .

As shown in Table 2, plasma levels of ET-1 were significantly higher in the DMT2 group than in the control group $(0.79 \pm 1.63 \mathrm{pg} / \mathrm{ml}$ vs. $0.33 \pm 0.08 \mathrm{pg} /$ $\mathrm{ml}$, respectively; $\mathrm{P}_{\mathrm{CD}}=0.049$ ). In addition, there were significant differences in ET-1 levels between the siblings $(0.75 \pm 1.26 \mathrm{pg} / \mathrm{ml})$ and the controls $\left(\mathrm{P}_{\mathrm{CS}}=0.031\right)$, but not between the siblings and the DMT2 patients $\left(\mathrm{P}_{\mathrm{SD}}=0.751\right)$.

Plasma sICAM-1 levels were similar in the DMT2 patients $(71.15 \pm 27.20 \mathrm{ng} / \mathrm{ml})$ and the siblings $(62.08 \pm$ $\left.26.37 \mathrm{ng} / \mathrm{ml} ; \mathrm{P}_{\mathrm{SD}}=0.411\right)$, but lower in the controls $\left(34.57 \pm 22.56 \mathrm{ng} / \mathrm{ml} ; \mathrm{P}_{\mathrm{CD}}=0.001\right)$. Data analysis also revealed a significant difference in SICAM-1 levels between the siblings and the control subjects $\left(\mathrm{P}_{\mathrm{CS}}=0.002\right)$, and between the DMT2 patients and the control subjects $\left(\mathrm{P}_{\mathrm{CD}}=0.001\right)$, as indicated in Table 2. Levels of endothelial expression of $\mathrm{sE}$-selectin were higher in the DMT2 subjects $(22.45 \pm 11.57 \mathrm{ng} / \mathrm{ml})$ than in the siblings $(16.56 \pm 8.71 \mathrm{ng} / \mathrm{ml})$ and the control $(16.28 \pm 7.50 \mathrm{ng} / \mathrm{ml})$ subjects $\left(\mathrm{P}_{\mathrm{SD}}=0.028\right.$ and $\mathrm{P}_{\mathrm{CD}}=0.026$, respectively $)$. Furthermore, no significant differences in sE-selectin concentrations were observed between the two groups of siblings and controls $\left(\mathrm{P}_{\mathrm{CS}}=0.919\right)$.

\section{Discussion}

Researchers have reported that FDRs of DMT2 patients are more likely to show impaired endothelial function in the resistance vessels than those with no family history of the condition [24]. Ostergård et al. showed that healthy, but insulin-resistant FDRs of DMT2 subjects predisposed for DMT2 show minor signs of endothelial dysfunction [25]. More recently, Caballero et al. [26] demonstrated early abnormalities in vascular reactivity and biochemical markers of endothelial cell activation in individuals at risk of developing DMT2. Cellular adhesion molecules are poorly expressed by the resting endothelium, but are up-regulated during inflammatory atherogenesis and may be an index of endothelial activation or even a molecular of early atherosclerosis [27]. The results indicated that the concentrations of ET-1 and sICAM-1 were significantly higher in the FDRs of DMT2 subjects than in the control subjects. In patients with DMT2, endothelial cell dysfunction is detectable very early in the course of the disease, even before overt hyperglycemia ensues, and may play a key function in the etiopathology of the vasculopathy reported with DMT2. The expression of VCAM-1, sICAM-1, and sEselectin plays a role in the initiation of the inflammatory process [28]. However, only a few studies have examined the development and progression of endothelial dysfunction in siblings of DMT2 patients. We found a highly significant plasma level of ET-1 and SICAM-1 in the siblings of DMT2 subjects. It is also possible that some genetic abnormalities leading to endothelial dysfunction could be present in individuals with family history of DMT2, although another study found that only those FDRs with demonstrable insulin resistance had endothelial dysfunction [29]. We have demonstrated that FDRs of DMT2 patients involve factor (s) capable of inducing the expression of ET-1 and sICAM-1 in endothelial cells. This effect cannot be directly attributed to hyperglycemia.

Table 2 Levels of endothelial function variables in DMT2, Sibling and controls

\begin{tabular}{|c|c|c|c|c|c|c|}
\hline Variable & Control & Siblings & DMT2 & $P_{C S}$ & $P_{C D}$ & $P_{S D}$ \\
\hline ET-1 (pg/ml) & $0.33 \pm 0.08$ & $0.75 \pm 1.26$ & $0.79 \pm 1.63$ & 0.031 & 0.049 & 0.751 \\
\hline sICAM-1 (ng/ml) & $34.57 \pm 22.56$ & $62.08 \pm 26.37$ & $71.15 \pm 27.2$ & 0.002 & 0.001 & 0.411 \\
\hline sE-selectin (ng/ml) & $16.28 \pm 7.50$ & $16.56 \pm 8.71$ & $22.45 \pm 11.57$ & 0.919 & 0.026 & 0.028 \\
\hline
\end{tabular}

DMT2 diabetes mellitus type $2, P_{C S} P$ value between controls and siblings, $P_{C D} P$ value between controls and DMT2, $P_{S D} P$ value between DMT2 and siblings 
Increased expression of ET-1 and sICAM-1 may have a role in the development of endothelial dysfunction in the siblings of DMT2 subjects. The present study also shows that Et-1 and sICAM-1 are sensitive markers of endothelial activation, in contrast to sE-selectin. In a study by Dai $\mathrm{Wu}$ et al. [30], the levels of E-selectin, vascular cell adhesion molecule-1 (VCAM-1), total cholesterol, and triglyceride were significantly elevated in FDR group compared with controls. There were endothelial dysfunction, activation of adhesion molecule, and insulin resistance in FDRs, and endothelial dysfunction is positively related to insulin resistance. Similarly, Gómez et al. designed another study in order to demonstrate whether FDRs of DMT2 subjects present markers as a form of precocious indicators of diabetes mellitus. They showed ICAM-1 and VCAM-1 to be significantly higher in the diabetic group, but not in the family group [31]. Our study should be interpreted within the context of its possible limitations such as low number of subjects in the groups.

\section{Conclusions}

We showed that the subjects with DMT2 have higher ET1 and sICAM-1 levels than the controls. Moreover, significant increase of ET-1 and sICAM-1 in the siblings showed the high ability of these markers in evaluating endothelial function. In addition, sICAM-1 and sE-selectin levels correlated with blood glucose. This finding confirms the importance of glycaemic milieu in determining circulating levels of endothelial function markers.

\section{Abbreviations}

DMT2, Diabetic mellitus type 2; ET-1, Endothelin-1; FDR, First-degree relative; sICAM-1, Soluble inter- cellular adhesion molecule-1

\section{Acknowledgements}

We would like to thank all the patients who kindly participated in the study.

\section{Funding}

This work supported by research grant from the Urmia University of Medical Sciences, Urmia, Iran.

\section{Availability of data and materials}

We uploaded the raw data as a supplementary file.

\section{Authors' contributions}

YR and ES proposed the concept of study. KEN and YR did the analytical aspects of the study. YR and ASh analyzed the results. Initial draft of the manuscript was written by KEN, MSM, which was reviewed and edited by YR and NV. All authors read and approved the final manuscript.

\section{Competing interests}

The authors declare that they have no competing interests.

\section{Consent for publication}

We have not data regarding Consent for publication, but we asked the patients to participation in a Scientific Research.

\section{Ethics approval and consent to participate}

We included the statement of Medical Ethics and consent to participate on Method-Subjects section.

\section{Author details}

${ }^{1}$ Cellular and Molecular Research Center, Urmia University of Medical Sciences, Urmia, Iran. ${ }^{2}$ Department of Biochemistry, Faculty of Medicine, Urmia University of Medical Sciences, Urmia, Iran. ${ }^{3}$ Department of Biology, Faculty of Science, Mashhad Payame-Noor University, Mashhad, Iran. ${ }^{4}$ Department of Endocrinology, Faculty of Medicine, Urmia University of Medical Sciences, Urmia, Iran. ${ }^{5}$ Department of Physiology, Faculty of Medicine, Urmia University of Medical Sciences, Urmia, Iran.

${ }^{6}$ Neurophysiology Research Center, Urmia University of Medical Sciences, Urmia, Iran.

Received: 25 August 2015 Accepted: 19 June 2016

Published online: 30 June 2016

\section{References}

1. Negro R. Endothelial effects of antihypertensive treatment: focus on irbesartan. Vasc Health Risk Manag. 2008;4(1):89-101.

2. Deanfield JE, Halcox JP, Rabelink TJ. Endothelial function and dysfunction: testing and clinical relevance. Circulation. 2007;115(10):1285-95.

3. Ludmer PL, Selwyn AP, Shook TL, Wayne RR, Mudge GH, Alexander RW, et al. Paradoxical vasoconstriction induced by acetylcholine in atherosclerotic coronary arteries. N Engl J Med. 1986;315(17):1046-51.

4. Endemann DH, Schiffrin EL. Endothelial dysfunction. J Am Soc Nephrol. 2004;15(8):1983-92.

5. De Mattia G, Bravi MC, Laurenti O, Cassone-Faldetta M, Proietti A, De Luca $\mathrm{O}$, et al. Reduction of oxidative stress by oral $\mathrm{N}$-acetyl-L-cysteine treatment decreases plasma soluble vascular cell adhesion molecule-1 concentrations in non-obese, non-dyslipidaemic, normotensive, patients with non-insulindependent diabetes. Diabetologia. 1998;41(11):1392-6.

6. Cosentino F, Luscher TF. Endothelial dysfunction in diabetes mellitus. J Cardiovasc Pharmacol. 1998;32 Suppl 3:S54-61.

7. Watts GF, Playford DA. Dyslipoproteinaemia and hyperoxidative stress in the pathogenesis of endothelial dysfunction in non-insulin dependent diabetes mellitus: an hypothesis. Atherosclerosis. 1998;141(1):17-30.

8. Steiner M, Reinhardt KM, Krammer B, Ernst B, Blann AD. Increased levels of soluble adhesion molecules in type 2 (non-insulin dependent) diabetes mellitus are independent of glycaemic control. Thromb Haemost. 1994; 72(6):979-84.

9. Hattori Y, Kasai K, Nakamura T, Emoto T, Shimoda S. Effect of glucose and insulin on immunoreactive endothelin-1 release from cultured porcine aortic endothelial cells. Metab Clin Exp. 1991;40(2):165-9.

10. Ferri C, Pittoni V, Piccoli A, Laurenti O, Cassone MR, Bellini C, et al. Insulin stimulates endothelin-1 secretion from human endothelial cells and modulates its circulating levels in vivo. J Clin Endocrinol Metab. 1995;80(3): 829-35.

11. Collins T, Williams A, Johnston Gl, Kim J, Eddy R, Shows T, et al. Structure and chromosomal location of the gene for endothelial-leukocyte adhesion molecule 1. J Biol Chem. 1991;266(4):2466-73.

12. Robbins S, Cotran R, Kumar V, Collins T. Robbins pathologic basis of disease. Philadelphia: WB Saunders; 1999.

13. Bella J, Kolatkar PR, Marlor CW, Greve JM, Rossmann MG. The structure of the two amino-terminal domains of human ICAM-1 suggests how it functions as a rhinovirus receptor and as an LFA-1 integrin ligand. Proc Natl Acad Sci U S A. 1998:95(8):4140-5.

14. Sarman B, Toth M, Somogyi A. Role of endothelin-1 in diabetes mellitus. Diabetes Metab Rev. 1998;14(2):171-5.

15. Hopfner RL, Gopalakrishnan V. Endothelin: emerging role in diabetic vascular complications. Diabetologia. 1999;42(12):1383-94.

16. Schiffrin EL, Intengan HD, Thibault G, Touyz RM. Clinical significance of endothelin in cardiovascular disease. Curr Opin Cardiol. 1997;12(4):354-67.

17. Köbberling J, Tillil H. Lorenz HADRCPS, 1985. 20. Genetics of type 2 A- and type 2. B-diabetes mellitus. Diabetes Res Clin Pract. 1985;1(2):20.

18. Haffner SM, Stern MP, Hazuda HP, Mitchell BD, Patterson JK. Increased insulin concentrations in nondiabetic offspring of diabetic parents. N Engl J Med. 1988;319(20):1297-301.

19. Kriketos AD, Greenfield JR, Peake PW, Furler SM, Denyer GS, Charlesworth JA, et al. Inflammation, insulin resistance, and adiposity: a study of first-degree relatives of type 2 diabetic subjects. Diabetes Care. 2004;27(8):2033-40.

20. Vaag A, Henriksen JE, Beck-Nielsen H. Decreased insulin activation of glycogen synthase in skeletal muscles in young nonobese Caucasian first- 
degree relatives of patients with non-insulin-dependent diabetes mellitus. J Clin Invest. 1992;89(3):782-8.

21. Florez JC, Hirschhorn J, Altshuler D. The inherited basis of diabetes mellitus: implications for the genetic analysis of complex traits. Annu Rev Genomics Hum Genet. 2003;4:257-91.

22. Diabetes mellitus. Report of a WHO Study Group. World Health Organ. Tech Rep Ser. 1985;727:1-113.

23. Declaration of Helsinki. Recommendations guiding doctors in clinical research. Adopted by the World Medical Association in 1964. Wis Med J. 1967;66(1):25-6.

24. Sonne MP, Hojbjerre L, Alibegovic AA, Vaag A, Stallknecht B, Dela F. Impaired endothelial function and insulin action in first-degree relatives of patients with type 2 diabetes mellitus. Metabolism. 2009;58(1):93-101.

25. Ostergard T, Nyholm B, Hansen TK, Rasmussen LM, Ingerslev J, Sorensen KE, et al. Endothelial function and biochemical vascular markers in first-degree relatives of type 2 diabetic patients: the effect of exercise training. Metabolism. 2006:55(11):1508-15.

26. Caballero AE, Arora S, Saouaf R, Lim SC, Smakowski P, Park JY, et al. Microvascular and macrovascular reactivity is reduced in subjects at risk for type 2 diabetes. Diabetes. 1999;48(9):1856-62.

27. El-Mesallamy H, Suwailem S, Hamdy N. Evaluation of C-reactive protein, endothelin-1, adhesion molecule (s), and lipids as inflammatory markers in type 2 diabetes mellitus patients. Mediat Inflamm. 2007;2007:73635.

28. Libby P. Inflammation in atherosclerosis. Nature. 2002;420(6917):868-74.

29. Balletshofer BM, Rittig K, Enderle MD, Volk A, Maerker E, Jacob S, et al. Endothelial dysfunction is detectable in young normotensive first-degree relatives of subjects with type 2 diabetes in association with insulin resistance. Circulation. 2000;101(15):1780-4.

30. Gomez JM, Vila R, Catalina P, Soler J, Badimon L, Sahun M. The markers of inflammation and endothelial dysfunction in correlation with glycated haemoglobin are present in type 2 diabetes mellitus patients but not in their relatives. Glycoconj J. 2008;25(6):573-9.

31. Dai W, Han X, Ye S, Liu K, Liu L, Ye J, et al. Adhesion molecule level and vascular endothelial function in first degree relatives of type 2 diabetes patients with normal glucose. China J Modern Med. 2010;1(21):3286-8.

\section{Submit your next manuscript to BioMed Central and we will help you at every step:}

- We accept pre-submission inquiries

- Our selector tool helps you to find the most relevant journal

- We provide round the clock customer support

- Convenient online submission

- Thorough peer review

- Inclusion in PubMed and all major indexing services

- Maximum visibility for your research

Submit your manuscript at www.biomedcentral.com/submit

) Biomed Central 